\title{
Análise dos Eventos Climáticos Extremos e de Suas Causas Climáticas para Redução de Riscos nas Bacias Hidrográficas Aguapeí e Peixe, São Paulo, Brasil
}

\author{
Osmar Evandro Toledo Bonfim ${ }^{1}$ (D), Djane Fonseca da Silva ${ }^{2}$ (D), Mary Toshie Kayano ${ }^{3}$ (D), \\ Lucas Henrique dos Santos Rocha ${ }^{2}$ \\ ${ }^{1}$ Centro de Ciências Naturais e Exatas, Universidade Federal de Santa Maria, Santa Maria, RS, \\ Brasil. \\ ${ }^{2}$ Instituto de Ciências Atmosféricas, Universidade Federal de Alagoas, Maceió, AL, Brasil. \\ ${ }^{3}$ Instituto Nacional de Pesquisa Espaciais, São Jose dos Campos, SP, Brasil.
}

Recebido em: 17 de Julho de 2020 - Aceito em: 11 de Agosto de 2020

\begin{abstract}
Resumo
Para melhorar nosso entendimento dos eventos extremos nas Bacias hidrográficas do rio Aguapeí e do rio do Peixe, utilizando análises estatísticas variadas, objetivou-se neste trabalho, detectar oscilações, sistemas ou fenômenos dominantes que influenciam na pluviometria e na ocorrência de eventos extremos nestas bacias, identificar tendências climáticas, e ainda detectar grupos que apresentam comportamento pluviométrico semelhante, utilizando o Método de agrupamento. Além disso, utilizou-se o SPI para análise de eventos extremos locais, cujas variações foram associadas ao El Niño-Oscilação Sul (ENOS) Canônico ou Modoki, e submeteu-se o índice de Prp às Análises de Ondaletas para identificar as causas climáticas da variabilidade pluviométrica. As análises das ondaletas identificaram picos significantes em 0,25 a 0,5 anos, embora uma escala de 22 anos predomine em quase todos os anos. Os anos com índices de precipitação elevados são decorrentes da associação de fenômenos de diferentes escalas temporais, como também, a falta destes, ocasionam anos de baixos índices pluviométricos. Foi constatada uma maior frequência de eventos de secas, contudo, a ocorrência de eventos chuvosos se mostrou de forma mais intensa. Os eventos de chuvas extremas ocorrem principalmente em anos de El Niño canônico, e eventos de secas leves em anos de La Niña Canônico.
\end{abstract}

Palavras-chave: análise de ondaletas, ENOS Canônico, ENOS Modoki, SPI.

\section{Analysis of Extreme Climate Events and Their Climate Causes for Risks Reduction in Aguapeí and Peixe Hydrographic Basins, São Paulo, Brazil}

\begin{abstract}
In order to improve our understanding on the extreme events of the hydrographic basins of river Aguapeí and river Peixe, using a variety of statistical analyzes, the objective of this work was to detect oscillations, systems or dominant phenomena that influence rainfall and the occurrence of extreme events in these hydrographic basins, to identify climatic trends, and groups with similar rainfall behavior using the Cluster analysis. In addition, SPI was used to analyze local extreme events, the variations of which were associated with the El Niño- South Oscillation (ENSO) Canonico or Modoki, and the Prp index was subjected to Wave Analysis to identify the climatic causes of rainfall variability. The wavelet analyses identified significant peaks at the 0.25 and 0.5 years although a 22-year time scale predominates during almost all years. Years with high rainfall rates are due to the association of different time scale phenomena, whereas their absences cause low rainfall years. A higher frequency of drought events was found, however, the occurrence of rainy events was more intense. Extreme rainy events occur mainly in canonical El Niño years, and light drought events in canonical La Niña years.
\end{abstract}

Keywords: wave analysis, ENOS Canonical, ENOS Modoki, SPI.

Autor de correspondência: Djane Fonseca da Silva, djane.silva@icat.ufal.br. 


\section{Introdução}

As chuvas extremas tem distribuição irregular, tanto temporalmente quanto espacialmente e causam grandes prejuízos, originando erosão no solo, inundações, prejuízos à agricultura e perda de colheitas (Araújo et al., 2008). Por outro lado, segundo Macedo et al. (2010), a seca é um fenômeno caracterizado pela falta de precipitação em certo período, que também provoca grave impacto social, econômico e ambiental.

De acordo com o relatório do Painel Intergovernamental sobre Mudanças do Clima (IPCC, 2014; IPCC, 2019) as mudanças climáticas naturais e antropogênicas estão provocando o aquecimento global que leva à intensificação na frequência de eventos extremos e esses estão fortemente relacionados ao alto número de emissões dos gases do efeito estufa.

A região Sudeste do Brasil (SEB) encontra-se em uma área vulnerável à ocorrência de eventos climáticos extremos, tais como episódios de chuvas severas e inundação (Marengo, 2016). De acordo com Rolim et al. (2007) o Estado de São Paulo, devido ao seu relevo acidentado, posição geográfica e influências de diferentes massas de ar, apresenta uma alta variabilidade climática e pluviométrica.

O Oeste Paulista, área de estudo, está submetido à maioria dos fenômenos meteorológicos e climáticos que afetam o Brasil por estar localizado em uma região de transição climática (Grimm e Ferraz, 1998; Boin, 2000). Os efeitos de fenômenos climáticos como o El Niño- Oscilação Sul (ENOS) são menos intensos se comparados aos das regiões Sul e Nordeste do Brasil (Minuzzi et al., 2006), porém esses fenômenos, associados a outros modos de variabilidade (Andreoli e Kayano, 2005), intensificam ou atenuam os sistemas meteorológicos e causam a variabilidade pluviométrica na região, afetando o setor energético, a economia e a população urbana.

As Bacias hidrográficas Aguapeí e Peixe, situadas no Oeste paulista, tem como principais atividades econômicas a pecuária extensiva e o cultivo da cana-de açúcar, que são importantes para a economia da região. Anualmente intensas chuvas que ocorrem especialmente no verão, provocam erosões, inundações e deslizamentos de terra que afetam principalmente a infraestrutura da região, resultando em bloqueios de rodovias e rupturas de pontes. Para o setor agrícola o excesso de chuva afeta tanto o plantio como a colheita das culturas como milho, café, cana de açúcar e hortaliças.

A aplicação da análise de ondaletas se torna um método eficaz para identificar os mecanismos que influenciam nos totais pluviométricos da região, compreendendo o funcionamento dos mesmos e identificando os ciclos climáticos atuantes na série de precipitação. Já através do teste de Mann-Kendall é possível verificar as modificações significativas nas tendências climáticas e apontar as áreas mais vulneráveis a essas alterações. O método de agrupamento permite detectar grupos que apresentam comportamento pluviométrico semelhante evidenciando as áreas homogêneas a fim de enriquecer o entendimento climático das Bacias. Por fim, a aplicação do índice de precipitação normalizada (SPI) busca identificar e quantificar os eventos extremos ocorridos nas Bacias hidrográficas Aguapeí e Peixe

Desse modo, a utilização de técnicas e análises estatísticas nas séries de precipitação das Bacias hidrográficas Aguapeí e Peixe visa auxiliar nos planejamentos energético e econômico da região, para obtenção de um melhor aproveitamento dos recursos hídricos e demanda de água para a agricultura e população, pois trará informações mais precisas e inéditas para a área. Identificando causa e impacto dos eventos extremos locais, também visa a adoção de práticas mitigatórias e preventivas em relação aos possíveis eventos climáticos extremos que possam atingir a região, evitando assim perdas econômicas e de vidas humanas.

\section{Material e Métodos}

A área de estudo (Fig. 1) é a Bacia hidrográfica do Rio Aguapeí, que possui uma área de $13.196 \mathrm{~km}^{2}$ e situase entre as coordenadas geográficas $21^{\circ} 20^{\prime}$ a $22^{\circ} 11^{\prime}$ de latitude Sul e $51^{\circ} 07^{\prime}$ a $51^{\circ} 19^{\prime}$ de longitude Oeste, e a Bacia hidrográfica do Rio do Peixe, com área de $10.769 \mathrm{~km}^{2}$, situada entre as coordenadas geográficas $21^{\circ} 44^{\prime}$ a $22^{\circ} 21^{\prime}$ de latitude Sul e $51^{\circ} 19^{\prime}$ a $51^{\circ} 50^{\prime}$ de longitude Oeste; ambas localizadas no Planalto ocidental paulista, região oeste do Estado de São Paulo (CBH-AP, 2014).

Foram utilizados dados pluviométricos para o período de 1958 a 2015 de 18 estações representativas espacialmente da Bacia hidrográfica Aguapeí-Peixe (Tabelas 1 e 2), Estado de São Paulo, provenientes da Agência Nacional das Água (ANA). Com a série de precipitação foram feitos gráficos climatológicos, análise de ondaletas,

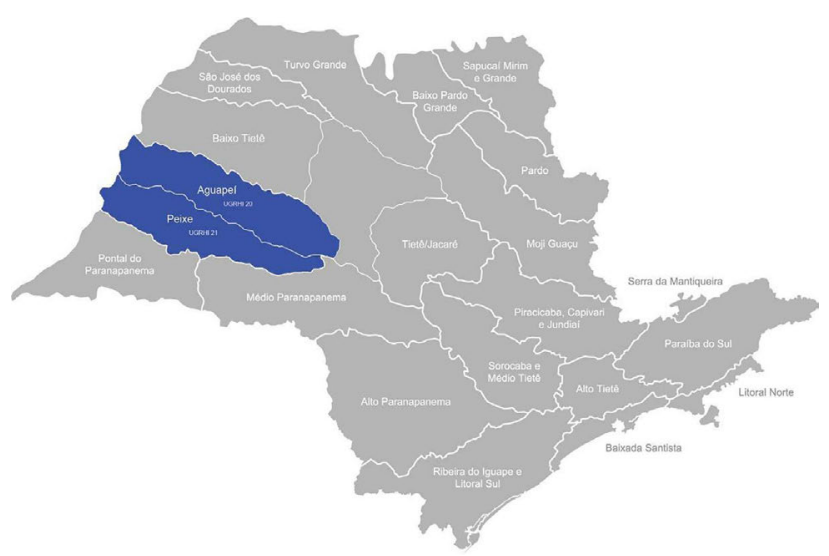

Figura 1 - Bacias hidrográficas do rio Aguapeí e rio do Peixe, localizadas na Região oeste do Estado de São Paulo. 
Tabela 1 - Estações pluviométricas Bacia hidrográfica Rio do Peixe usadas no estudo.

\begin{tabular}{llll}
\hline \multicolumn{4}{c}{ Bacia hidrográfica Rio do Peixe } \\
\hline Estações & Região & Latitude & Longitude \\
\hline Adamantina & Baixo Peixe & $21^{\circ} 68 \mathrm{~S}$ & $51^{\circ} 08 \mathrm{~W}$ \\
Bastos & Médio Peixe & $21^{\circ} 91 \mathrm{~S}$ & $50^{\circ} 73 \mathrm{~W}$ \\
Echaporã & Médio Peixe & $22^{\circ} 43 \mathrm{~S}$ & $50^{\circ} 21 \mathrm{~W}$ \\
Emilianópolis & Baixo Peixe & $21^{\circ} 83 \mathrm{~S}$ & $51^{\circ} 48 \mathrm{~W}$ \\
Marília & Alto Peixe & $22^{\circ} 21 \mathrm{~S}$ & $49^{\circ} 93 \mathrm{~W}$ \\
Osvaldo Cruz & Médio Peixe & $21^{\circ} 80 \mathrm{~S}$ & $50^{\circ} 86 \mathrm{~W}$ \\
Presidente Prudente & Baixo Peixe & $22^{\circ} 09 \mathrm{~S}$ & $51^{\circ} 38 \mathrm{~W}$ \\
Presidente Venceslau & Baixo Peixe & $21^{\circ} 88 \mathrm{~S}$ & $51^{\circ} 83 \mathrm{~W}$ \\
Rancharia & Médio Peixe & $21^{\circ} 94 \mathrm{~S}$ & $50^{\circ} 93 \mathrm{~W}$ \\
\hline
\end{tabular}

Tabela 2 - Estações pluviométricas da Bacia hidrográfica Rio Aguapeí usadas no estudo.

\begin{tabular}{llll}
\hline \multicolumn{4}{l}{ Bacia hidrográfica Rio Aguapeí } \\
\hline Estações & Região & Latitude & Longitude \\
\hline Clementina & Médio Aguapeí & $21^{\circ} 56 \mathrm{~S}$ & $50^{\circ} 45 \mathrm{~W}$ \\
Castilho & Baixo Aguapeí & $20^{\circ} 86 \mathrm{~S}$ & $51^{\circ} 48 \mathrm{~W}$ \\
Dracena & Baixo Aguapeí & $21^{\circ} 46 \mathrm{~S}$ & $51^{\circ} 53 \mathrm{~W}$ \\
Garça & Alto Aguapeí & $22^{\circ} 19 \mathrm{~S}$ & $49^{\circ} 65 \mathrm{~W}$ \\
Getulina & Alto Aguapeí & $21^{\circ} 69 \mathrm{~S}$ & $50^{\circ} 30 \mathrm{~W}$ \\
Guaraçaí & Baixo Aguapeí & $21^{\circ} 03 \mathrm{~S}$ & $51^{\circ} 20 \mathrm{~W}$ \\
Guararapes & Médio Aguapeí & $21^{\circ} 26 \mathrm{~S}$ & $50^{\circ} 63 \mathrm{~W}$ \\
Monte Castelo & Baixo Aguapeí & $21^{\circ} 29 \mathrm{~S}$ & $51^{\circ} 56 \mathrm{~W}$ \\
Queiroz & Médio Aguapeí & $21^{\circ} 80 \mathrm{~S}$ & $50^{\circ} 23 \mathrm{~W}$ \\
\hline
\end{tabular}

aplicação do teste de Mann-Kendall, aplicação do método de agrupamento e a utilização do SPI para identificação e quantificação dos eventos extremos, além de classificá-los de acordo com a sua intensidade.

Após tratamento e organização dos dados, foi utilizado o método de Análise de agrupamentos, que tem por finalidade agrupar indivíduos em número limitado de classes, de forma que os indivíduos pertencentes a essas classes mantenham características semelhantes em algum aspecto (Guimarães et al., 2013). Utilizou-se o software SPSS e o método hierárquico. Desta forma, gerou-se o Dendograma (Fig. 2), o qual uniu os indivíduos mais semelhantes e apontou os não semelhantes, por meio da distância euclidiana. Desta forma, apontou-se quais as estações que formariam os grupos de maior semelhança dentro da Bacia hidrográfica (Fig. 3) e essa informação foi útil para distinguir na Bacia hidrográfica, áreas homogêneas climatologicamente.

Após a Análise de agrupamentos gerou-se o "boxplot" (gráfico de caixa), que é um gráfico utilizado para avaliar a distribuição empírica dos dados e realiza uma análise comparativa dos dados amostrais de cada grupo. $\mathrm{O}$ "boxplot" é formado pelo primeiro e terceiro quartil e pela mediana. As hastes inferiores e superiores se estendem, respectivamente, do quartil inferior até o menor valor não inferior ao limite inferior e do quartil superior até o maior valor não superior ao limite superior. Essa estatística também funciona muito bem para a identificação e eliminação de valores discrepantes (Santos et al., 2011).

Foram submetidas às análises de ondaletas $(\mathrm{AO})$ as séries de precipitação dos 2 grupos (Fig. 3) para todo o período de dados, com intuito de identificar ciclos ou oscilações, e podem fornecer uma indicação clara de qual escala temporal domina os sistemas/fenômenos meteorológicos ao longo das séries.

O índice de precipitação primeiramente deve ser tratado antes de submetido à AO. Esse índice é a anomalia da variável, calculada a partir da climatologia mensal e normalizada pelo desvio padrão (Kousky e Chu, 1978; Aceituno, 1988; Andreoli et al., 2004; Da Silva, 2009):

$$
A \operatorname{Var}_{i, j}=\left(\operatorname{Var}_{i, j}-\operatorname{Var}_{i}\right) \sigma_{i}
$$

em que $A \operatorname{Var}_{i, j}$ é a anomalia da variável, no ano $j=1,2,3$, $\ldots, \mathrm{N}$ e mês $i=1,2,3, \ldots 12$; $\operatorname{Var}_{i, j}$ é a variável no ano $j=1,2,3 \ldots, \mathrm{N}$ e mês $i=1,2,3, \ldots 12$, o qual foi calculado sua anomalia; $\operatorname{Var}_{i}$ é a média climatológica no mês a ser calculado a anomalia e $\sigma_{i}$ é o desvio padrão de cada mês $i$ específico.

O termo ondaleta, ondeleta ou wavelet estende-se a um conjunto de funções com forma de pequenas ondas produzidas por dilatações e translações de uma função simples $\psi_{(t)}$ de variável real $t$, eventualmente chamada de ondaleta-mãe ou ondaleta básica.

A ondaleta Morlet é complexa e possui características semelhantes aos de sinais meteorológicos, tais como simetria ou assimetria e variação temporal brusca ou suave. Estes critérios são adotados para a utilização da ondaleta para identificações de variações em escalas sinóticas, oscilações intra-sazonais e outras variações meteorológicas de diferentes escalas temporais (Weng e Lau, 1994) e é definida pela seguinte expressão, também utilizada em Da Silva (2017):

$$
\Psi(t)=e^{i W 0 t} e^{\frac{-t^{2}}{2}}
$$

a qual representa uma onda modulada por um envelope Gaussiano. Em que: $i=$ parâmetro de dilatação e compressão da onda; $W 0=$ parâmetro de frequência $\mathrm{e}$ $t=$ tempo. Todos introduzidos no 'script' de programação do software Matlab.

O teste de Mann-Kendall (Kendall, 1975; Mann, 1945) é indicado pela Organização Meteorológica Mundial (OMM) na avaliação de tendências significativas em séries dados temporais compatíveis com aplicações ambientais, e foi usado em dados das 18 estações distribuídas em toda Bacia hidrográfica. 


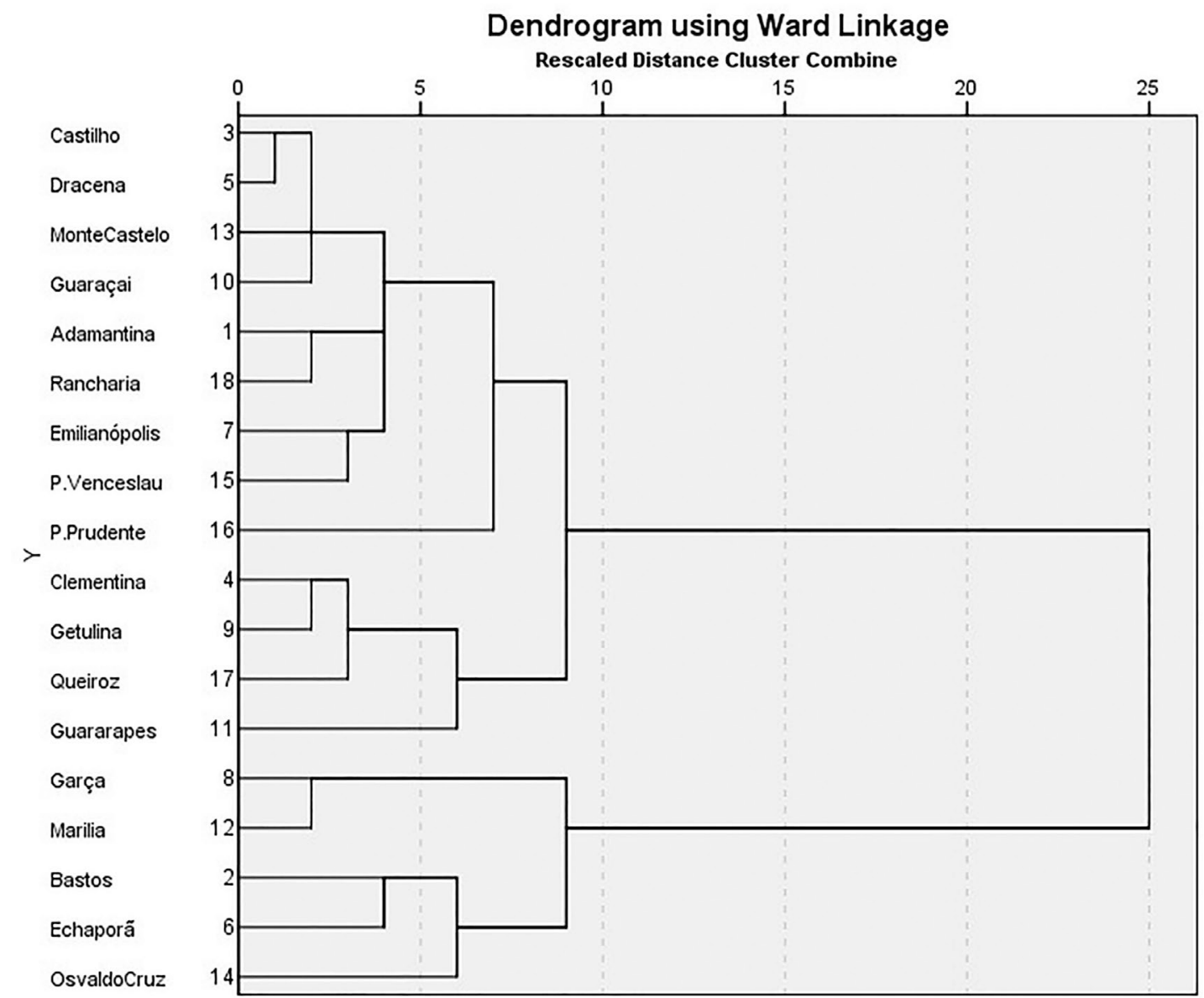

Figura 2 - Dendograma das Bacias hidrográficas Aguapeí-Peixe

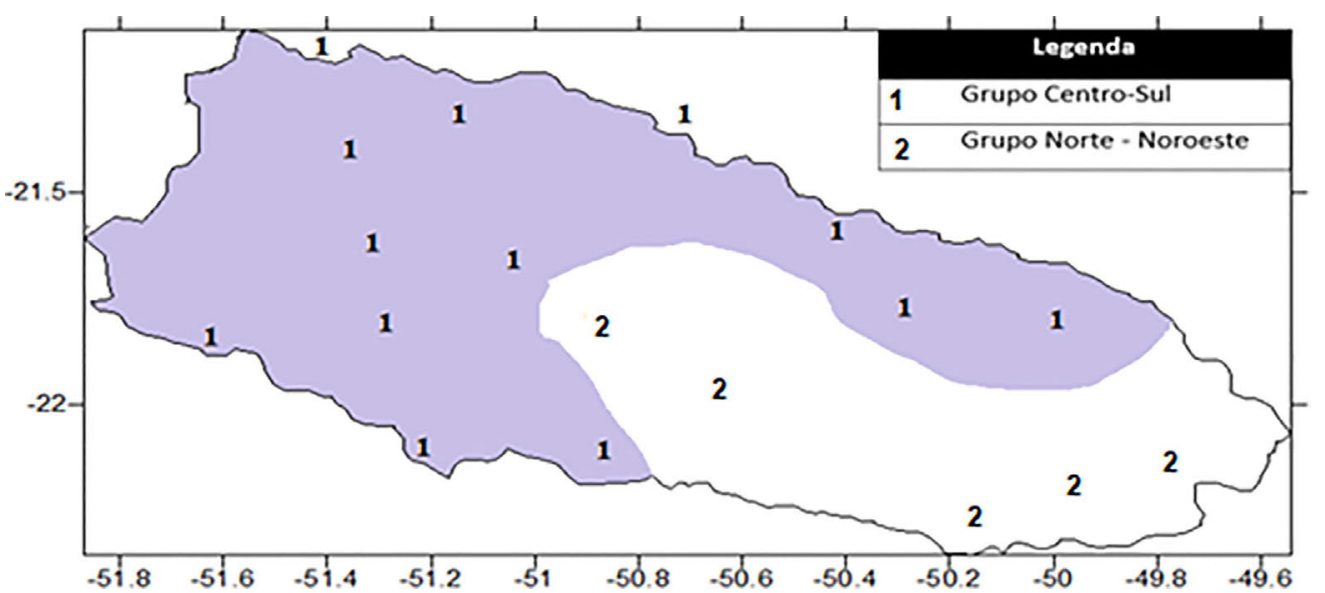

Figura 3 - Espacialização dos grupos climáticos homogêneos nas Bacias hidrográficas Aguapeí- Peixe (SP). Eixo X são as longitudes e Eixo Y são as latitudes.

Esse teste é largamente usado para testar tendências em séries temporais hidrológicas e climatológicas (Chattopadhyay e Edwars, 2016). A estatística do teste é descrita em Silva et al. (2010):

$$
S=\sum_{i=2}^{n} \sum_{j=1}^{i=1} \operatorname{sign}\left(x_{i}-x_{j}\right)
$$

em que $x_{j}$ são os dados estimados da sequência de valores, $n$ é o comprimento da série temporal e o sinal $\left(x_{i}-x_{j}\right)$ é 
igual a -1 para $\left(x_{i}-x_{j}\right)<0,0$ para $\left(x_{i}-x_{j}\right)=0$, e 1 para $\left(x_{i}-\right.$ $\left.x_{j}\right)>0$.

Os níveis de significância de $p=0,01$ e 0,05 foram aplicados neste estudo. Uma estimativa não paramétrica para o valor da inclinação da tendência é obtida de acordo com Silva et al. (2010):

$$
\beta=\text { Median }\left[\frac{\left(X_{j}-X_{i}\right)}{(j-i)}\right] \text {, para } i<j
$$

em que $x_{j}$ e $x_{\mathrm{i}}$ são os pontos dados medidos no tempo $j$ e $i$, respectivamente.

Após o cálculo das tendências para todas as estações pluviométricas do estudo, foi gerado o mapa de distribuição espacial das mesmas, o que indica na bacia hidrográfica os locais com tendências positivas e negativas para precipitação.

$\mathrm{Na}$ tentativa de quantificar e caracterizar os eventos extremos de seca e chuva nas diferentes regiões do globo foram criados índices capazes de identificar tais eventos. McKee et al. (1993) propuseram o Índice de Precipitação Normalizada (SPI), utilizado para quantificar o déficit de precipitação em diversas escalas de tempo.

$$
g(x)=\frac{X^{\alpha-1} * e^{\frac{-x}{\beta}}}{\beta^{\alpha} \Gamma(\alpha)}, \text { para } X>0
$$

Em que: $\alpha>0$ parâmetro de forma; $\beta>0$ parâmetro de escala; $x>0$, a quantidade de precipitação $(\mathrm{mm})$ e $\Gamma(\alpha)$ a função gama completa. Para estimativa dos parâmetros $\alpha \mathrm{e}$ $\beta$ da distribuição gama utilizou-se o método:

$$
\alpha=\frac{1}{4 A}\left(1+\sqrt{1+\frac{4 A}{3}}\right) e \hat{\beta}=\frac{\bar{x}}{\alpha},
$$

sendo $\bar{x}$ a precipitação média e

$$
A=\ln (\bar{x})-\frac{\sum \ln (x)}{n}
$$

em que o $n$ é número de observações.

Deste modo, a distribuição acumulativa é então transformada em distribuição probabilidade normal com média igual a zero e desvio padrão igual a um. Em seguida, a probabilidade acumulada de ocorrência de cada valor mensal é estimada. Aplica-se a essa probabilidade a função normal inversa para encontrar o valor do SPI.

De acordo com Santos et al. (2017), o SPI nada mais é que a diferença da precipitação observada menos à média do intervalo de tempo específico, dividida pelo desvio padrão, conforme Eq. (8):

$$
S P I=Z i=\frac{(P i-\overline{P i})}{\sigma i}
$$

em que $P i$ - Precipitação mensal no período, $\overline{P i}$ - Precipitação média do período em questão e $\sigma_{i}$ - desvio padrão da série histórica de precipitação.

Após o cálculo do SPI, a precipitação total mensal para um período de tempo específico recebe um valor adimensional correspondente a uma classe. Os valores de SPI positivos significam superioridade à média de precipitação, enquanto valores negativos significam menor que a média de precipitação e o valor zero corresponde à precipitação média. Na Tabela 3 são ilustradas as categorias de SPI, de acordo com as descritas por McKee et al. (1993).

Após a caracterização dos eventos através da aplicação do SPI (Tabela 3), os mesmos serão relacionados com os anos definidos como El Niño (EN) ou La Niña (LN), Canônico ou Modoki, a fim de averiguar a influência dos diferentes tipos de ENOS na ocorrência de eventos extremos.

Neste estudo foi utilizado o método de Yeh et al. (2009), o qual define EN Modoki (LN Modoki) quando a anomalia de TSM da região Niño $4\left(160^{\circ} \mathrm{E}-150^{\circ} \mathrm{W}, 5^{\circ} \mathrm{N}\right.$ - $5^{\circ} \mathrm{S}$ ) está acima de $0,5^{\circ} \mathrm{C}$ (abaixo de $-0,5^{\circ} \mathrm{C}$ ) e que seja maior (menor) que a anomalia da TSM da região Niño 3 $\left(150^{\circ} \mathrm{W}-90^{\circ} \mathrm{W}, 5^{\circ} \mathrm{N}-5^{\circ} \mathrm{S}\right)$. Já EN Canônico (LN Canônico), Yeh et al. (2009) definem quando a anomalia da TSM da região Niño 3 está acima de $0,5{ }^{\circ} \mathrm{C}$ (abaixo de $-0,5^{\circ} \mathrm{C}$ ) e que seja maior (menor) do que a anomalia da TSM da região Niño 4. Assim, os 'anos neutros' (AN), foram considerados aqueles sem ocorrência do ENOS Modoki e Canônico (Tabela 4).

Deve ser lembrado que, tanto esse método de classificação de ENOS Canônico ou Modoki estabelecido por Yeh et al. (2009), quanto o de Ashok et al. (2007) e utilizado por Tedeschi (2013), só começam a classificar esses diferentes tipos de ENOS em 1982; assim, neste trabalho, com os dados utilizados sendo de 1958 a 2015, só foram classificados como Canônico ou Modoki os que estão no período de 1982-2015.

Tabela 3 - Classificação dos períodos secos e chuvosos segundo classes de SPI.

\begin{tabular}{ll}
\hline Valores de SPI & Classes \\
$<-2,00$ & Seca Extrema \\
$-1,99$ a $-1,50$ & Seca Severa \\
$-1,49$ a $-1,00$ & Seca Moderada \\
$-0,99$ a $-0,49$ & Seca Leve \\
$-0,48$ a 0,49 & Quase normal \\
0,50 a 0,99 & Chuva Leve \\
1,00 a 1,49 & Chuva moderada \\
1,50 a 1,99 & Chuva Severa \\
$>2,00$ & Chuva Extrema \\
\hline
\end{tabular}


Tabela 4 - El Niño Canônico (vermelho), El Niño Modoki (alaranjado), La Niña Canônico (azul escuro) e La Niña Modoki (azul claro) de 1982 a 2016 de acordo com o método de Yeh et al. (2009).

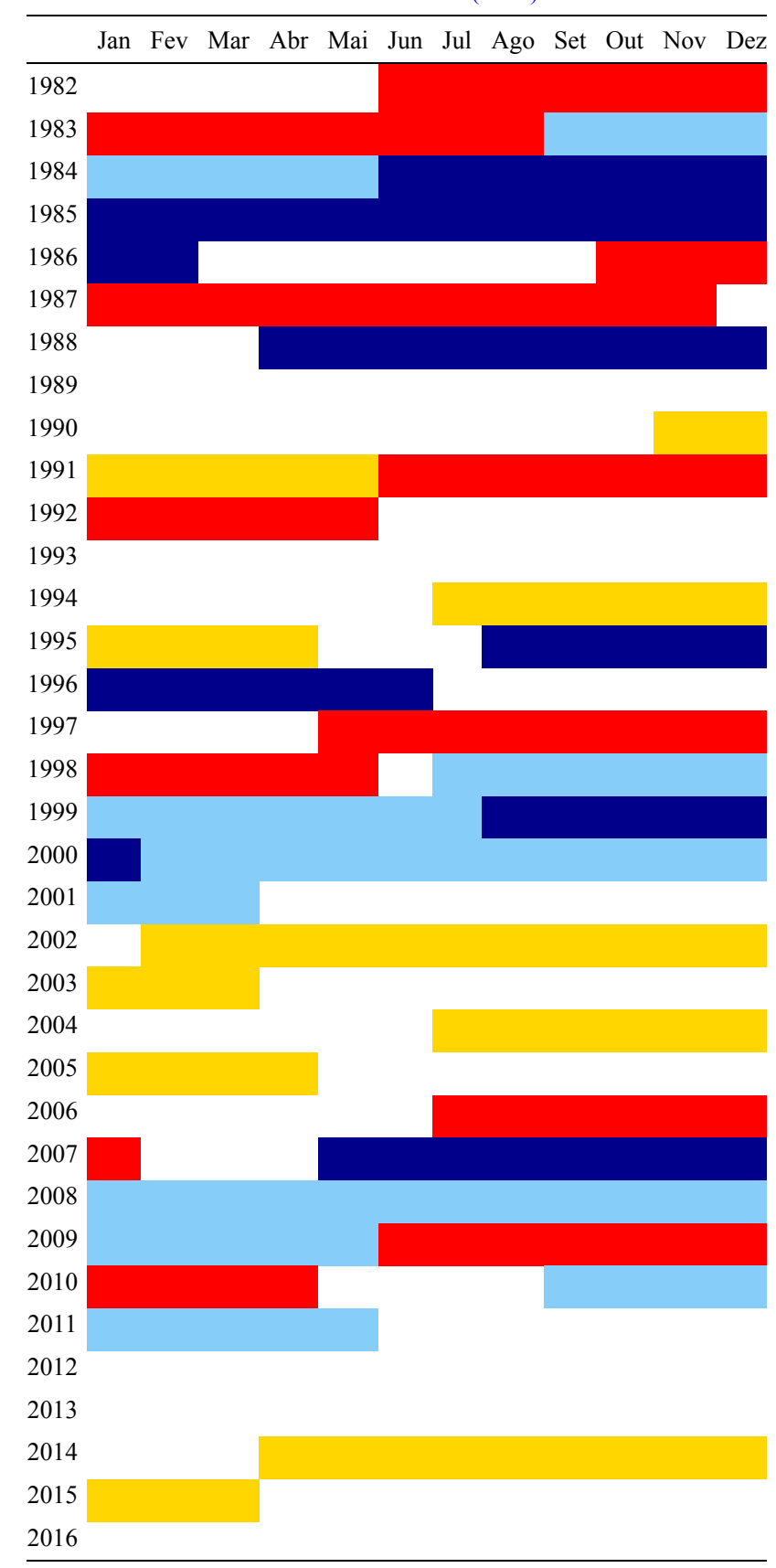

\section{Resultados e Discussões}

No Dendograma (Fig. 2), o eixo das abcissas indica a distância euclidiana e no eixo das ordenadas estão distribuídas as estações. Na medida em que a distância euclidiana aumenta, o nível de semelhança no comportamento entre séries temporais diminui. Foram identificadas as estações pluviométricas que tem semelhança direta entre si: as estações 3 (Castilho) e 5 (Dracena), as quais apresentaram uma moderada semelhança com as estações 13 (Monte Castelo) e 10 (Guaraçaí). Do mesmo modo, as es- tações 1 (Adamantina) e 18 (Rancharia) e as estações 7 (Emilianópolis) e 15 (Presidente Venceslau) demonstraram semelhança não tão direta entre si e também com as estações 13 e 10. A estação 16 (Presidente Prudente) apresentou-se de forma isolada uma semelhança não tão direta com as estações citadas anteriormente formando assim o subgrupo 1 .

O subgrupo 2, formado pelas estações 4 (Clementina), 9 (Getulina), 17 (Queiroz) e 11 (Guararapes), apresentou semelhança não tão direta com o subgrupo 1 , a junção desses dois subgrupos formam um conjunto de estações pluviométricas, o grande grupo 1.

Outro grande grupo, o grupo 2, é composto pelas estações que formam o agrupamento e tem semelhança não tão direta das estações 8 (Garça), 12 (Marilia), 2 (Bastos), 6 (Echaporã) e 14 (Osvaldo Cruz). Analisando o Dendograma observou-se que os dois grupos se assemelham indiretamente, uma vez que apresentaram uma maior distância euclidiana entre eles; deste modo, nas Bacias hidrográficas do Rio Aguapeí e do Rio do Peixe há 2 grupos climáticos homogêneos e distintos entre eles (Fig. 3).

Para fortalecer os resultados encontrados pelas Figs. 2 e 3, elaborou-se o Boxplot para precipitação dos Grupos 1 e 2 das Bacias hidrográficas Aguapeí-Peixe (Fig. 4). Essa estatística mostra que o Grupo 1 apresenta limite superior de precipitação maior que o do Grupo 2, chegando a $148 \mathrm{~mm}$, enquanto Grupo 2 atingiu $130 \mathrm{~mm}$. Já o limite inferior foi $73 \mathrm{~mm}$ para Grupo 1 e $71 \mathrm{~mm}$ para Grupo 2; Já a mediana dos grupos foram $115 \mathrm{~mm}$ para Grupo 1 e $100 \mathrm{~mm}$ para Grupo 2.

O primeiro quartil do Grupo $1 \mathrm{em} 100 \mathrm{~mm}$, indica que $25 \%$ dos dados da amostra chegam a esse valor, e o terceiro quartil indica que $75 \%$ dos dados atingem até $129 \mathrm{~mm}$. Para o Grupo 2, o primeiro quartil chega a $90 \mathrm{~mm}$, indicando que $25 \%$ dos dados pluviométricos desse grupo atingem até esse valor; ao tempo que o terceiro percentil atingindo o valor de $109 \mathrm{~mm}$, indica que $75 \%$ dos dados do Grupo 2 chegam a esse valor, que é menor até que a mediana do Grupo 1 e menor que o terceiro percentil do Grupo $1 \mathrm{em} 20 \mathrm{~mm}$.

Desse modo, os eventos extremos do Grupo 1, principalmente os extremos de chuva, são mais intensos que os do Grupo 2, e assim os gestores podem elaborar planos de ações e planejar obras mitigadoras de impactos no local.

$\mathrm{O}$ índice de precipitação para o Grupo 1 (Fig. 5) apresentou a dominância da escala de 22 anos em quase todos os anos, porém o pico espectral nesta escala não é estatisticamente significante, já que está fora do cone de influência.

De acordo com Oliveira et al. (2017) há uma estreita relação entre fenômenos cíclicos e de origem astronômica e alterações climáticas na Terra. Em Beer et al. (2000) os autores revelam que além do ciclo solar de Schwabe (11 anos), o astro apresenta um ciclo solar que é um ciclo magnético no qual a polarização magnética das manchas 
solares se inverte a cada 22 anos, o chamado ciclo de Hale, o qual pode ser relacionado com essa escala dominante de
22 anos citada anteriormente. No mesmo sentido, Zuffo (2015) afirmou que esse ciclo apresenta influência signifi-

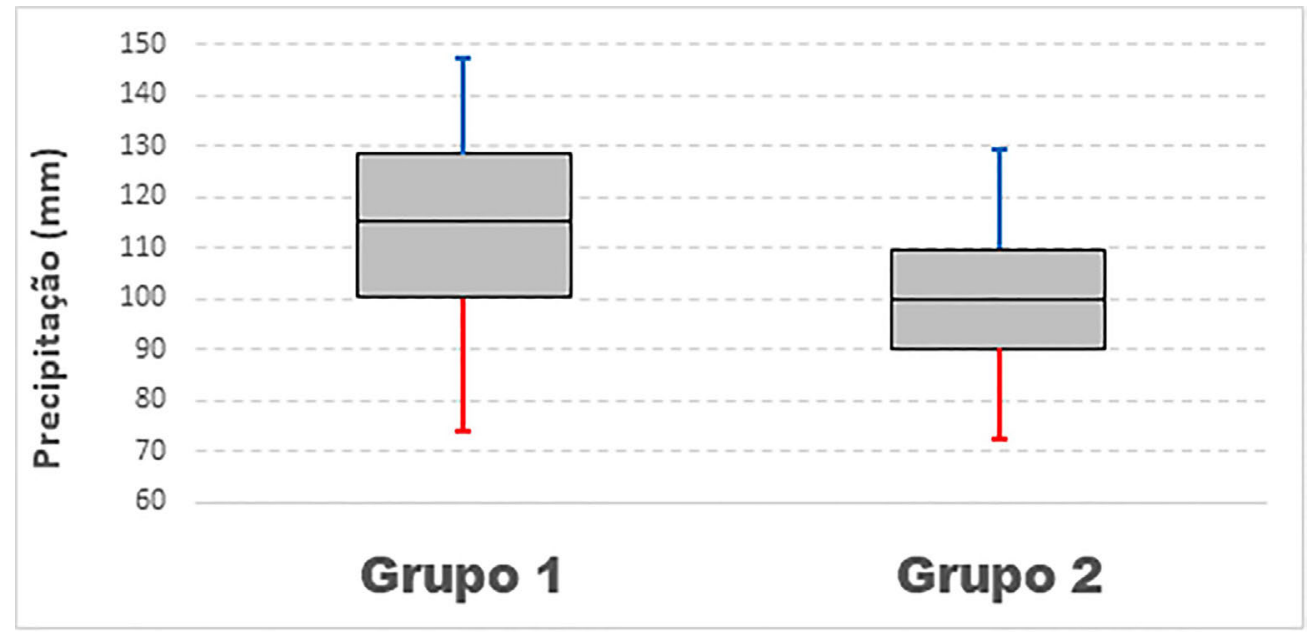

Figura 4 - Boxplot para precipitação dos Grupos 1 e 2 das Bacias hidrográficas Aguapeí-Peixe (SP).
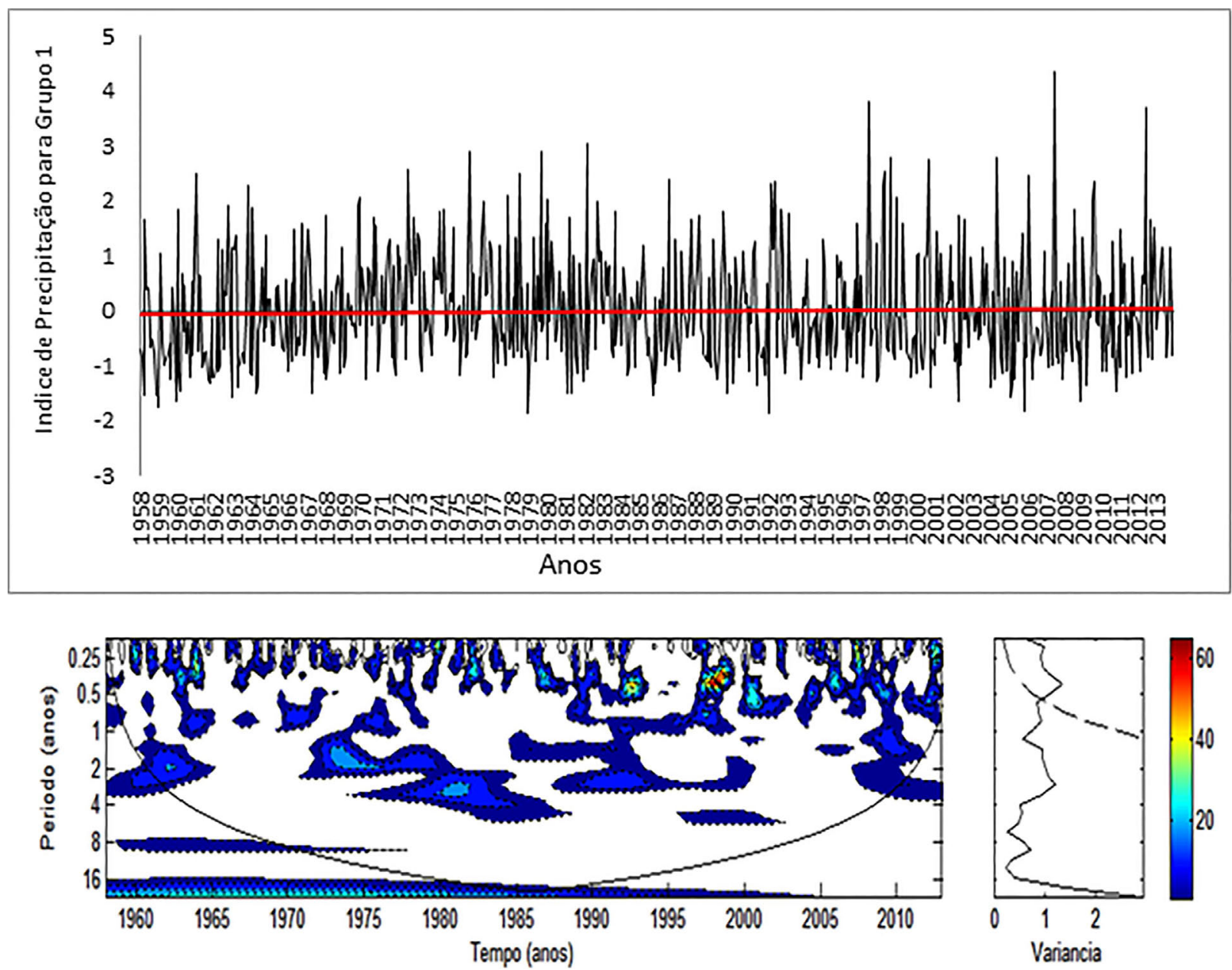

Figura 5 - a) Índice de Precipitação (Prp) para Grupo 1; b) Espectro de Energia local para Prp. A curva em forma de U representa o cone de influência, sob a qual o efeito de borda é importante; c) Espectro Global de Wavelet, o contorno tracejado indica que o Espectro Global de Wavelet é significativo a nível de 95\%. 
cativa dos efeitos do Sol no clima da Terra, uma vez que representa uma forçante radiativa considerável nas mudanças climáticas.

Scafetta $(2010 ; 2012)$ e Oliveira et al. (2017) também já relacionaram a escala de 22 anos à Oscilação Interdecadal do Pacífico (OIP), que apresenta um ciclo variando entre 15 e 30 anos e afeta tanto o norte quanto o sul do Pacífico.

Os picos espectrais significantes ocorrem nas escalas de 0,25 a 0,5 anos, sazonal a semestral. Nos anos de 1979, 1985/86, 1991/92 e 2002 notou-se que a ausência da escala sazonal propiciou picos negativos de precipitação, como foi discutida nos trabalhos de Gershunov e Barnett (1998) e Silva e Da Silva (2016), Da Silva et al. (2020).

Nos anos de 1960, 1964, 1972, 1976, 1998 e 2007 observou-se picos positivos de precipitação (Fig. 5a) associados à presença simultânea das escalas de 22 anos, 11 anos e 2-7 anos e a escala de 0,25 a 0,5 anos, com exceção da escala de 11 anos para o ano de 1998 e 2007 . A união das escalas temporais promove altos índices de precipitação, respaldando os resultados encontrados por Rock- wood e Maddox (1988), Gershunov e Barnett (1998), Da Silva (2009) e Silva e Da Silva (2016).

As escalas temporais identificadas na série do Grupo 2 (Fig. 6a), através das análises das ondaletas, foram a escala de aproximadamente 22 anos, que se apresentou dominante; a escala de 2 a 7 anos relacionada ao sinal do ENOS, e sendo a de 7 anos provavelmente relacionadas com eventos de ENOS estendido e Dipólo do Atlântico (Clauzet e Wainer, 1999); a escala de 11 anos, a qual está associada ao ciclo de manchas solares (Kerr, 1996; Molion, 2005) e também ao Dipolo do Atlântico (Souza et al., 1998; Servain et al., 1999); entretanto, a atuação do Dipolo não foi verificada influenciando diretamente a precipitação no Sul/Sudeste do país. Por fim, identificou-se a ocorrência da escala sazonal a semestral de 0,25-0,5 anos, cujos picos espectrais são estatisticamente significantes.

Esses eventos extremos ocorreram em sua maioria devido à ocorrência simultânea de fenômenos de várias escalas temporais como atestaram Rockwood e Maddox (1988) ou devido ocorrência dos fenômenos climáticos em mesma fase, conforme Gershunov e Barnett (1998) e enfa-
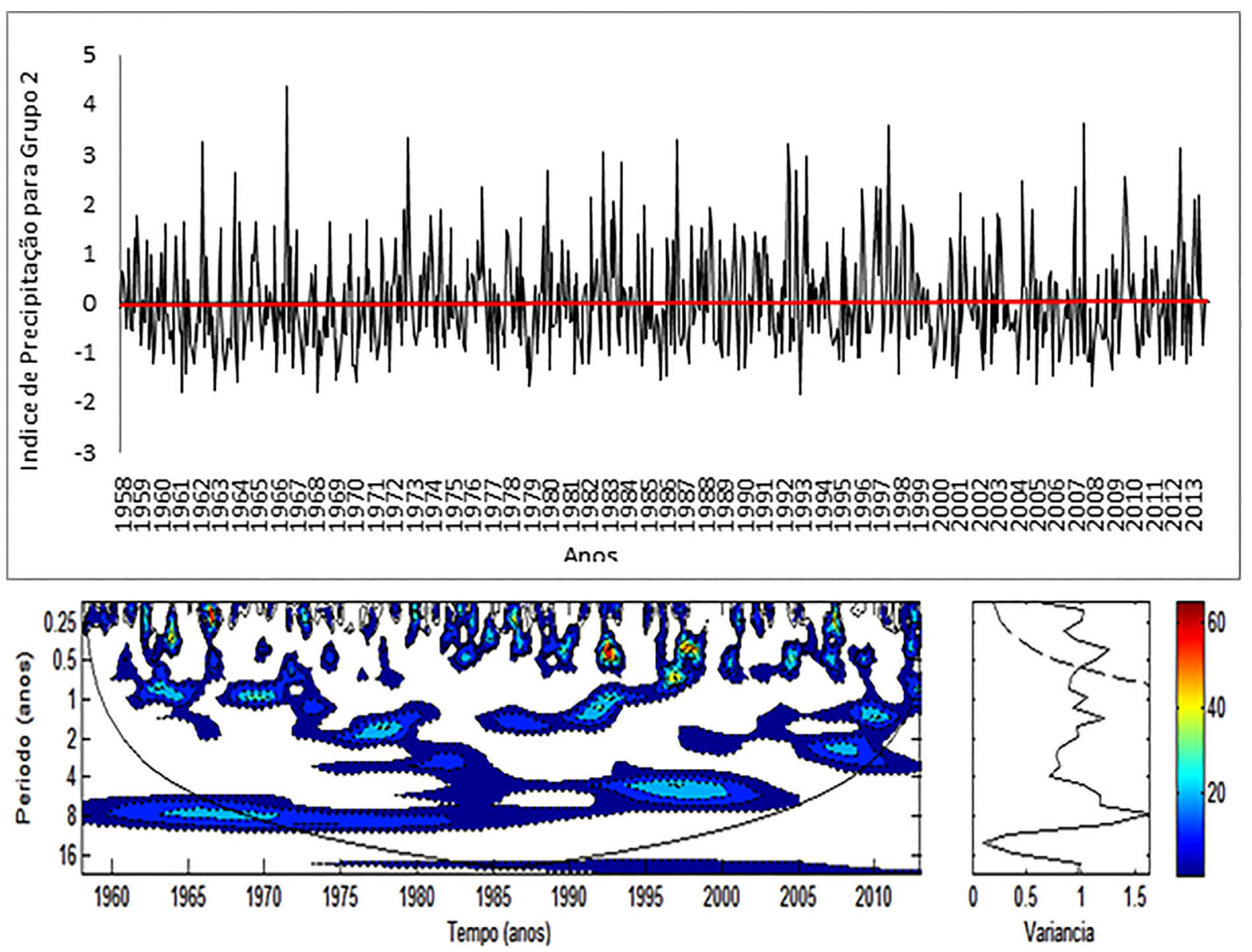

Figura 6 - a) Índice de Precipitação (Prp) para Grupo 2; b) Espectro de Energia local para Prp. A curva em forma de U representa o cone de influência, sob a qual o efeito de borda é importante; c) Espectro Global de Wavelet, O contorno tracejado indica que o Espectro Global de Wavelet é significativo a nível de $95 \%$. 
tizado por Da Silva, Kayano e Sousa (2010), os quais utilizaram esse método estatístico para acompanhamento e prevenção de riscos em bacia hidrográfica.

Para o Grupo 2 (Fig. 6) as escalas dominantes foram a de 22 anos e a do ENOS. A escala de 11 anos mostrou-se presente na série no período de 1958 a 1986. Observou-se também as escalas de 2-7 anos e de 0,25-0,5 anos atuando no período de 1958 a 2013.

Nos anos de 1961 e 1968 observou-se índices negativos de precipitação e não foi detectada a atuação da escala de 22 anos neste período (Fig. 6a). A interação entre escalas desfavoráveis à precipitação propiciou a redução da escala sazonal causando picos negativos de precipitação. Já a união das escalas temporais $(22,11$ e ENOS) simultaneamente promoveram os altos índices de precipitação e intensificação da escala sazonal nos anos de 1966, 1992, 1998 e 2007; exceto a escala de 22 anos para o ano de 1966. Rockwood e Maddox (1988) e Da Silva (2009), também observaram essa mesma relação.

Neste item, já que com utilização de tabelas, há espaço disponível, optou-se por calcular tendências para todas estações utilizadas no estudo.
$\mathrm{Na}$ Bacia hidrográfica do rio do Peixe foram detectadas tendências de aumento nas precipitações em todas as estações pluviométricas analisadas (Tabela 5). Estas tendências positivas de precipitação significam que as chuvas que ocorreram vêm aumentando gradativamente ao longo do tempo. Em Adamantina, por exemplo, em todo o período de 55 anos, a precipitação aumentou $2,04 \mathrm{~mm}$, enquanto para Presidente Venceslau o aumento na precipitação foi de $5,17 \mathrm{~mm}$. Na aplicação do Teste de T-Student a estação pluviométrica de Emilianópolis foi a única que não apresentou significância estatística em sua tendência de aumento.

Para a Bacia hidrográfica do Rio Aguapeí o teste de Mann-Kendall também indicou tendências crescentes nas precipitações em todas as estações analisadas (Tabela 6). A estação de Dracena apresentou um aumento de $1,20 \mathrm{~mm}$ na precipitação em toda a série de 55 anos e para Guararapes o aumento foi de $9,08 \mathrm{~mm}$, o maior aumento entre todas estações, para todo o período analisado. No teste TStudent todas as estações pluviométricas apresentaram significância estatística em suas tendências de aumento.

A crescente demanda por recursos naturais, especialmente os recursos hídricos, associada ao crescimento

Tabela 5 - Tendências encontradas nas séries de precipitação da B.H. do Rio do Peixe para o período de 1958 a 2015, usando o Teste de Mann-Kendall, e resultado do teste de significância de T-Student ao nível de $95 \%$.

\begin{tabular}{lcc}
\hline Cidades Bacia hidrográfica Rio do Peixe & Tendências de Precipitação por Mann-Kendall (mm) & Teste de Significância T-Student \\
\hline Adamantina & 2,04 & Aumento - com significância estatística \\
Bastos & 1,27 & Aumento - com significância estatística \\
Echaporã & 2,33 & Aumento - com significância estatística \\
Emilianópolis & 0,47 & Aumento - sem significância estatística \\
Marília & 3,57 & Aumento - com significância estatística \\
Osvaldo Cruz & 3,90 & Aumento - com significância estatística \\
Pres. Prudente & 1,67 & Aumento - com significância estatística \\
Pres. Venceslau & 5,17 & Aumento - com significância estatística \\
Rancharia & 2,84 & Aumento - com significância estatística \\
\hline
\end{tabular}

Tabela 6 - Tendências encontradas nas séries de precipitação da B.H. do Rio Aguapeí para o período de 1958 a 2015 usando o Teste de Mann-Kendall e resultado do teste de significância de T-Student ao nível de $95 \%$.

\begin{tabular}{lcc}
\hline Cidades Bacia hidrográfica Aguapeí & Tendências de Precipitação por Mann-Kendall (mm) & Teste de Significância T-Student \\
\hline Castilho & 2,14 & Aumento - com significância estatística \\
Clementina & 5,17 & Aumento - com significância estatística \\
Dracena & 1,20 & Aumento - com significância estatística \\
Garça & 2,84 & Aumento - com significância estatística \\
Getulina & 1,82 & Aumento - com significância estatística \\
Guaraçaí & 2,29 & Aumento - com significância estatística \\
Guararapes & 9,08 & Aumento - com significância estatística \\
Monte Castelo & 1,76 & Aumento - com significância estatística \\
Queiroz & 7,34 & Aumento - com significância estatística
\end{tabular}


populacional, provoca uma necessidade cada vez maior de água para o desenvolvimento econômico e social da região. Por esse motivo, as tendências de aumento de precipitação contribuem para uma melhor distribuição e disposição de água nas Bacias hidrográficas AguapeíPeixe, pelo fato das tendências serem positivas em toda área, inclusive nas cabeceiras das Bacias, lugar em que se situa a cidade de Garça, região que se encontram as nascentes dos Rios do Peixe e Tibiriçá, afluentes do Rio Aguapeí.

No estudo de Haylock et al. (2006) foram observadas tendências crescentes de precipitação na maior parte do SEB e SB no período de 1960-2000, concordando com os trabalhos de Groissman et al. (2005), Sansigolo e Kayano (2010) e Marengo (2016), fato que corrobora os resultados obtidos neste trabalho.

Haylock et al. (2006) constataram que a região SEB e SB do Brasil estão experimentando um aumento na intensidade de eventos extremos, que acarreta aumento no número consecutivos de dias chuvosos e diminui o número consecutivo de dias secos. Marengo (2008) associa essa maior frequência de eventos extremos com os efeitos que a Zona de Convergência do Atlântico Sul (ZCAS) e os Jato de Baixos Níveis (JBN) exercem nas escalas intrasazonais e interanuais. Já Carvalho et al. (2004) observaram um maior número de eventos extremos durante anos de El Niño, nos quais, afetam diretamente a intensidade da ZCAS. Em geral, as Bacias hidrográficas do Rio Aguapeí e do Rio do Peixe encontram-se em uma área vulnerável à ocorrência de eventos climáticos extremos.

$\mathrm{Na}$ distribuição espacial de tendências positivas da Bacia hidrográfica do Rio Aguapeí e do Rio do Peixe (Fig. 7), a foz do Rio do Peixe localizada a sudoeste da Bacia hidrográfica apresentou tendências crescentes mais acentuadas se comparado ao noroeste da Bacia onde se encontra a foz do Rio Aguapeí. Portanto, a implementação de planos que visam o gerenciamento de recursos hídricos da Bacia hidrográfica do Rio Aguapeí-Peixe torna-se mais necessária na região onde se encontra a foz do Rio Aguapeí em consequência dos baixos valores apresentados de tendências crescentes de precipitação.

$\mathrm{Na}$ quantificação e caracterização dos eventos extremos na Bacia Hidrográfica Aguapeí-Peixe, através da aplicação do índice de SPI, os resultados mostraram que os eventos de secas foram os mais frequentes em todas as séries analisadas, em média, com $37,4 \%$ dos eventos extremos; todavia os anos normais totalizaram, em média $36,7 \%$, respaldando os trabalhos de Barra et al. (2002); Macedo et al. (2010) e Santos et al. (2017).

Para o Grupo 1 (Fig. 8), a distribuição de frequência do SPI quantificou 13 episódios de seca severa, 76 de seca moderada e 156 de seca leve, contudo não houve registro de seca extrema; totalizando 245 ocorrências, que corresponde a $36,46 \%$ dos eventos. Os eventos de chuvas foram distribuídos em 74 ocorrências de chuva leve, 52 de chuva moderada, 30 de chuva severa e 26 de chuva extrema; totalizando 182 episódios, equivalente a 27,08\% dos eventos.

No Grupo 1, um período semi prolongado de chuvas (Fig. 5a) ocorreu entre dezembro/1971 a dezembro/1974, em razão de ambas estações possuírem o mesmo comportamento climático (Bonfim e Da Silva, 2017), resultado da ocorrência de El Niño.

Os picos de precipitação extrema no Grupo 1 (Fig. 6a) ocorreram em junho/1997 e julho/2007 em que os valores de SPI $(>2,0)$ foram superiores a 3,8.

Para o Grupo 2 (Fig. 9) a distribuição de frequência do SPI quantificou 12 ocorrências de seca severa, 77 de seca moderada e 161 de seca leve; totalizando 250 ocorrências, que representa $37,2 \%$ dos eventos. Não houve

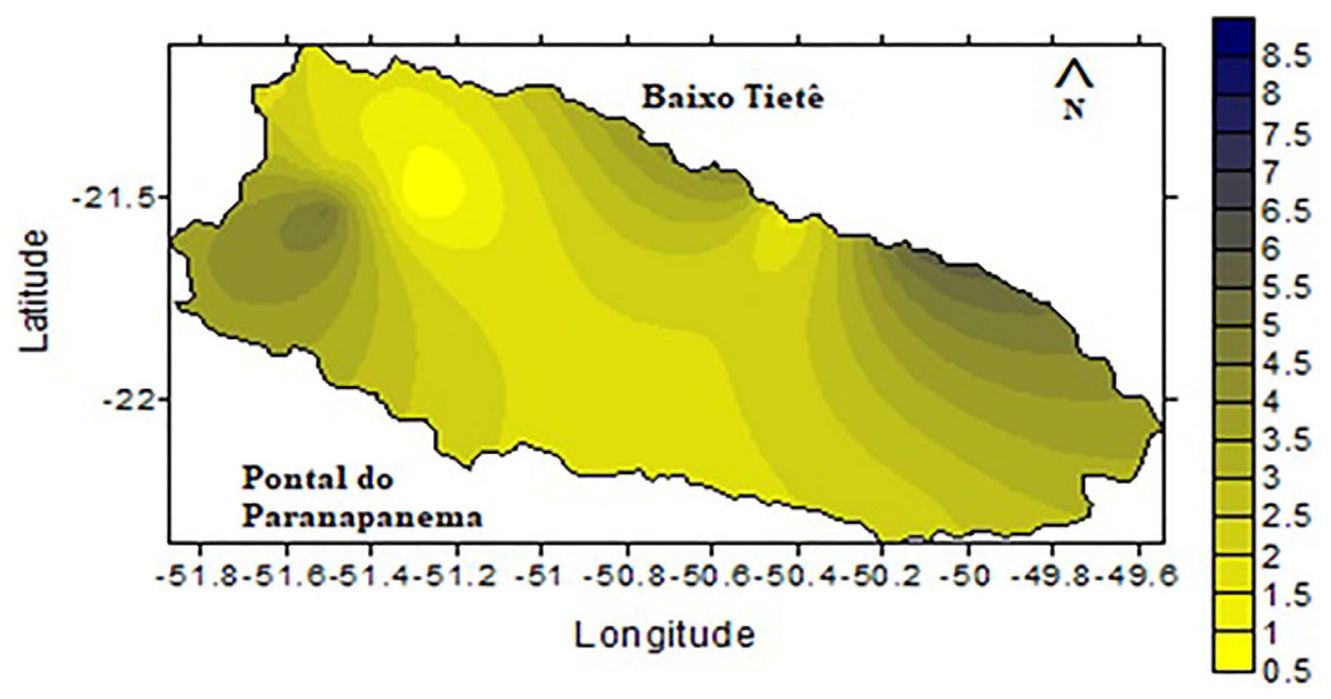

Figura 7 - Distribuição das tendências de precipitação nas B.H. Aguapeí-Peixe (SP). 


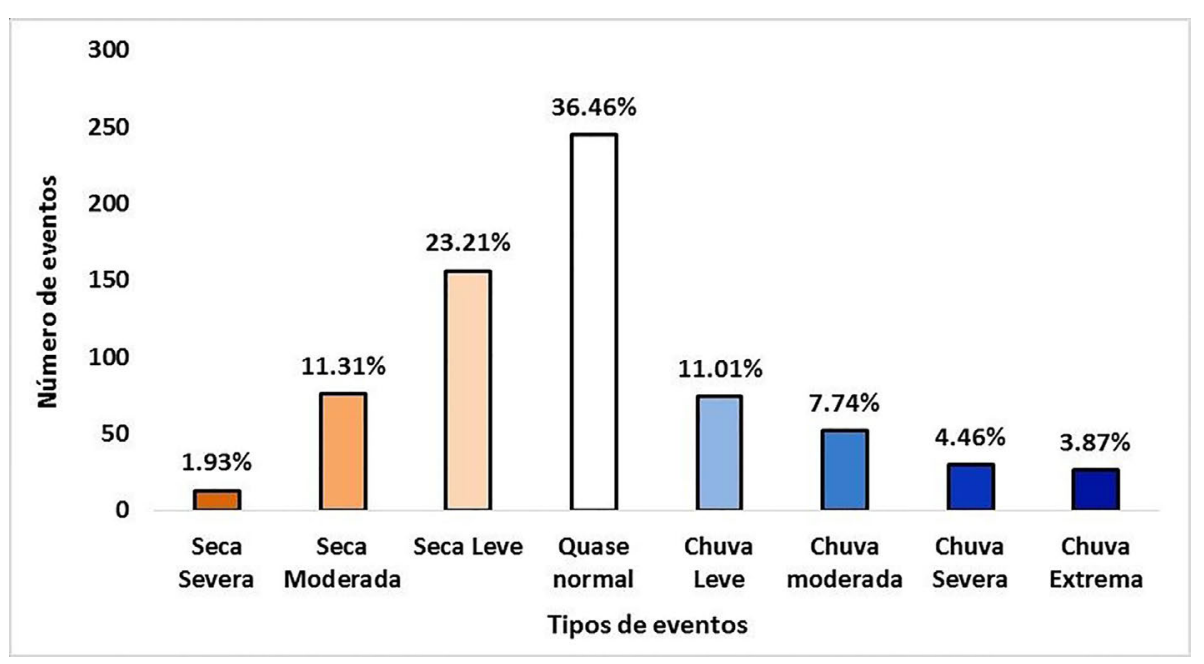

Figura 8 - Classificação e quantificação dos eventos climáticos extremos, segundo SPI, para Grupo 1.

registro de seca extrema. Na distribuição de eventos de chuvas notou-se 69 ocorrências de chuva leve, 46 de chuva moderada, 30 de chuva severa e 27 de chuva extrema; um total de 172 episódios de eventos de chuvas, que totaliza $25,42 \%$.

O maior período sequencial de chuvas no Grupo 2 (Fig. 6a) foi verificado de outubro/1975 a abril/1977 permanecendo por 19 meses, em que verifica-se prevalência de anos de El Niño, o que para o Sudeste do Brasil significa incremento de precipitação de acordo com Andreoli e Kayano (2005) e Kayano e Oliveira (2008). O maior período contínuo de seca ocorreu entre fevereiro/1968 a agosto/1969, já o período sequencial de chuvas ocorreu de outubro/1975 a outubro/1976.

Para um melhor entendimento sobre a influência dos tipos de ENOS (Canônico e Modoki) na ocorrência de episódios de chuvas ou secas computado pelo método SPI, a Tabela 7 demonstra a quantidade de episódios de seca e chuvas de acordo com a configuração e tipo do ENOS no período de 1982 a 2015, conforme explicado na metodologia e utilizando o método de Yeh et al. (2009). As secas severas ocorreram, na maior parte, em anos classificados como La Niña canônica (LNCa), e anos de El Niño Modoki (ENm). Os anos de ENm reduz a precipitação entre os meses de setembro a fevereiro na região Sudeste do Brasil segundo estudo de Tedeschi et al. (2016).

Nos eventos de secas moderadas os anos de LNCa mostraram-se com maior influência, contudo anos de ENm ainda tiveram forte atuação na ocorrência deste tipo de seca. As secas leves ocorreram predominantemente nos anos de LNCa, corroborando com Tedeschi (2013) e Tedeschi et al. (2016). Desse modo, secas severas e moderadas ocorreram mais no período no Grupo 2, enquanto no Grupo 1, foram maioria as secas levas (Tabela 7).

Os eventos de chuvas (leve, moderada e severa) ocorreram em geral em anos de El Niño Canônico

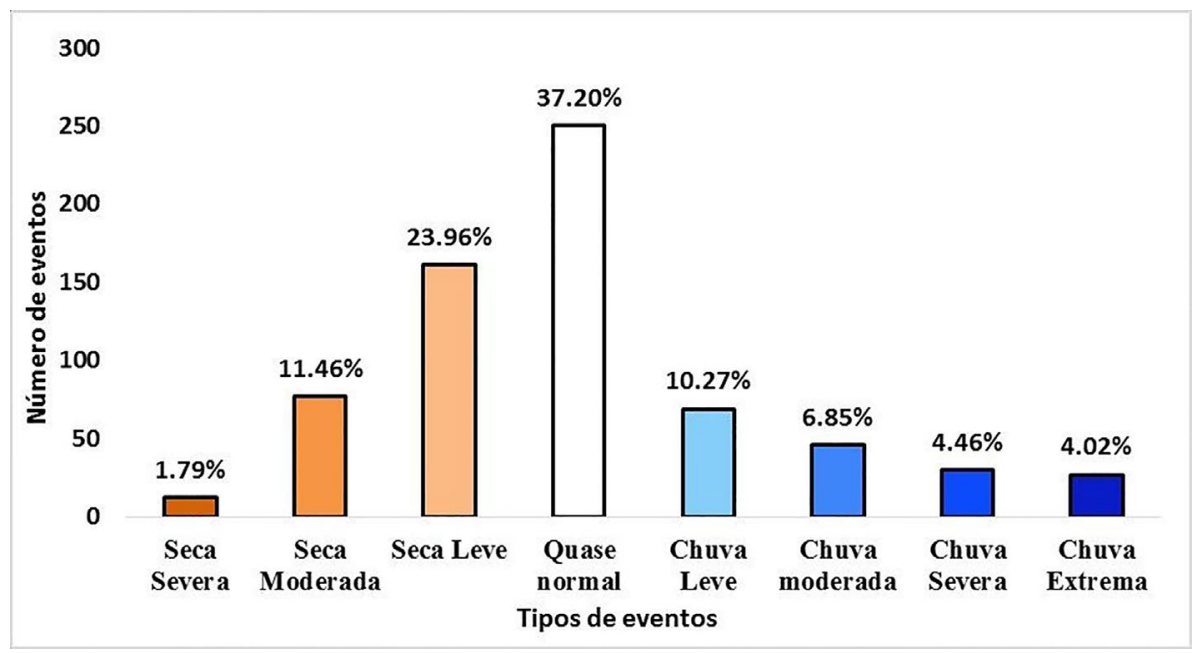

Figura 9 - Classificação e quantificação dos eventos climáticos extremos, segundo SPI, para Grupo 2. 
Tabela 7 - Ocorrência de eventos de acordo com o tipo de ENOS, nos Grupos período de 1982 a 2015, utilizando método de Yeh et al. (2009).

\begin{tabular}{|c|c|c|c|c|}
\hline Evento & ENOS & Média Grupo 1 & Média Grupo 2 & Total B.H. \\
\hline \multirow[t]{4}{*}{ Seca Severa } & $\mathrm{ENCa}$ & 1 & 0 & 1 \\
\hline & $\mathrm{ENm}$ & 2 & 1 & 3 \\
\hline & LNCa & 1 & 2 & 3 \\
\hline & $\mathrm{LNm}$ & 1 & 2 & 3 \\
\hline \multirow[t]{4}{*}{ Seca Moderada } & $\mathrm{ENCa}$ & 3 & 5 & 8 \\
\hline & $\mathrm{ENm}$ & 9 & 6 & 15 \\
\hline & $\mathrm{LNCa}$ & 9 & 12 & 21 \\
\hline & $\mathrm{LNm}$ & 8 & 10 & 18 \\
\hline \multirow[t]{4}{*}{ Seca leve } & $\mathrm{ENCa}$ & 10 & 9 & 19 \\
\hline & $\mathrm{ENm}$ & 14 & 20 & 34 \\
\hline & $\mathrm{LNCa}$ & 29 & 21 & 50 \\
\hline & $\mathrm{LNm}$ & 25 & 16 & 41 \\
\hline \multirow[t]{4}{*}{ Chuva leve } & $\mathrm{ENCa}$ & 8 & 9 & 17 \\
\hline & $\mathrm{ENm}$ & 7 & 6 & 13 \\
\hline & $\mathrm{LNCa}$ & 8 & 7 & 15 \\
\hline & $\mathrm{LNm}$ & 2 & 7 & 9 \\
\hline \multirow[t]{4}{*}{ Chuva moderada } & $\mathrm{ENCa}$ & 7 & 4 & 11 \\
\hline & $\mathrm{ENm}$ & 3 & 4 & 7 \\
\hline & $\mathrm{LNCa}$ & 4 & 5 & 9 \\
\hline & LNm & 5 & 3 & 8 \\
\hline \multirow[t]{4}{*}{ Chuva severa } & $\mathrm{ENCa}$ & 2 & 7 & 9 \\
\hline & $\mathrm{ENm}$ & 1 & 4 & 5 \\
\hline & $\mathrm{LNCa}$ & 2 & 3 & 5 \\
\hline & $\mathrm{LNm}$ & 3 & 1 & 4 \\
\hline \multirow[t]{4}{*}{ Chuva extrema } & $\mathrm{ENCa}$ & 8 & 7 & 15 \\
\hline & ENm & 1 & 2 & 3 \\
\hline & $\mathrm{LNCa}$ & 2 & 2 & 4 \\
\hline & $\mathrm{LNm}$ & 3 & 2 & 5 \\
\hline
\end{tabular}

(ENCa), porém os anos de ENm, LNCa e LNm foram participativos para a ocorrência desses episódios de chuvas. Há ressalva para os casos de chuvas extremas que ocorreram predominantemente nos anos de $\mathrm{ENCa}$, tendo número bem superior aos demais eventos.

\section{Conclusões}

O conhecimento dos grupos homogêneos nas Bacias hidrográficas do Rio Aguapeí e do Rio do Peixe pode contribuir de maneira essencial para o gerenciamento de recursos hídricos. Uma vez que essas estações apresentaram o mesmo comportamento climático facilitando a compreensão espacial da precipitação. A presença de áreas homogêneas simplifica a aplicação de medidas em casos de cheias ou secas, além de auxiliar nas atividades agrícolas, armazenamento de água e energia para a região. No geral, as Bacias são compostas por 3 subgrupos com comportamento não tão semelhantes nas séries de precipitação e 2 grupos climáticos homogêneo com semelhança indireta (distintos) entre eles, o que contribui para a implementação de gestão hídrica e agrícola na região. Apontou-se também que os eventos extremos de chuva do Grupo 1 são mais intensos que do Grupo 2 na Bacia hidrográfica.

As análises das Ondaletas sugeriram suas causas climáticas evidenciando uma escala de 22 anos como a escala dominante na precipitação das Bacias hidrográficas, além da influência das escalas sazonal, de ENOS e do Ciclo de Manchas Solares. Os anos com índices de precipitação elevada são caracterizados pela associação de fenômenos de diferentes escalas temporais, como também a falta destes relaciona-se com os anos de baixos índices pluviométricos.

As alterações de tendências climáticas mostraram-se crescentes em todos os pontos analisados da Bacia hidrográfica Aguapeí-Peixe, evidenciando um aumento na demanda hídrica da mesma podendo suprir as necessidades do desenvolvimento econômico e da população. Contudo, os valores das tendências se apresentaram diferentes para cada região das Bacias hidrográfica, os menores valores foram observados a noroeste, onde se localiza a foz do Rio Aguapeí, indicando uma maior necessidade de adoção de planos de gestão hídrica para o noroeste da região.

Em todos os pontos analisados das Bacias hidrográficas Aguapeí e Peixe foi constatada uma maior frequência de eventos de secas, contudo, a ocorrência de eventos chuvosos se mostrou de forma mais intensa. Os eventos de chuvas extremas caracterizados pelo SPI ocorrem principalmente em anos de El Niño canônico e eventos de secas leves em anos de La Niña Canônico. Além disto, é importante salientar que os eventos chuvosos e secos aqui avaliados, estavam associados com a variabilidade climática ocorrido no Oceano Pacifico.

\section{Agradecimentos}

Os autores agradecem a Coordenação de Aperfeiçoamento de Pessoal de Nível Superior (CAPES) pelo apoio financeiro concedido durante e para a realização deste estudo.

\section{Referências}

ACEITUNO, P. On the functioning of the Southern Oscillation in the South American Sector. Part 1: Surface climate, Mon. Wea. Rev., v. 116, n. 3, p. 505-524, 1988.

ANDREOLI, R.V.; KAYANO, M.T.; GUEDES, R.L.; OYAMA, M.D.; ALVES, M.A.S. A influência da temperatura da superfície do mar dos Oceanos Pacífico e Atlântico na variabilidade de precipitação em Fortaleza, Revista Brasileira de Meteorologia, v. 19, n. 3, p. 337-344, 2004.

ANDREOLI, R.V.; KAYANO, M.T. Enso-related rainfall anomalies in South America and associated circulation features during warm and cold Pacific decadal oscillation regimes. Internacional Journal Climatology, v. 25, n. 15, p. 2017-2030, 2005. 
ARAÚJO, L.E.; SOUSA, F. DE A.S.; RIBEIRO, M.A.; SANTOS, A.S.; MEDEIROS, P.C. Análise estatística de chuvas intensas na bacia hidrográfica do Rio Paraíba. Revista Brasileira de Meteorologia, v. 23, n. 2, p. 162-169, 2008.

ASHOK, K; BEHERA, S.K.; RAO, S.A.; WENG, H.; YAMAGATA, T. El Niño Modoki and its possible teleconnection. Journal of Geophysical Research, v. 112, p. 1-27, 2007.

BARRA, T.D.S.; COSTA, J.M.N.; RAO, T.R.; SEDIYAMA, G.C.; FERREIRA, W.P.; DANTAS NETO, F.S. Caracterização climatológica da severidade de secas do estado do Ceará-Brasil. Campina Grande. Revista Brasileira de Engenharia Agrícola e Ambiental, v. 6, n. 2, p. 266-272, 2002.

BEER J.; MENDER W.; STELLMACHER, R. The role of the sun in climate forcing. Quaternary Science Reviews, v. 19, p. 403-415, 2000.

BOIN, M.N. Chuvas e Erosões no Oeste Paulista: Uma Análise Climatológica Aplicada. Tese de Doutorado em Geografia, IGCE - UNESP, Rio Claro, 2000.

BONFIM, O.E.T.; DA SILVA, D.F. Identificação de áreas de precipitação homogêneas nas bacias hidrográficas Aguapeí-Peixe (SP). In: VII Simpósio Internacional de Climatologia, Petrópolis. Anais do VII Simpósio Internacional de Climatologia, 2017.

CARVALHO, L.M.V.; JONES, C.; LIEBMANN, B. The South Atlantic Convergence Zone: persistence, intensity, form, extreme precipitation and relationships with intraseasonal activity. Journal of Climate, v. 17, n. 1, p. 88-108, 2004.

CBH-AP. Comitê das Bacias Hidrográficas dos Rios Aguapeí e Peixe. Relatório de Situação dos Recursos Hídricos 2014. Marília: CBH-AP, 2014.

CHATTOPADHYAY, S.; EDWARS, D.R. Long-term trend analysis of precipitation and air temperature for Kentucky, United States. Climate MDPI, v. 4, n. 10, p. 1-15, 2016.

CLAUZET, G.; WAINER, I. Identificação da variabilidade de baixa frequência em algumas regiões da costa sudeste-nordeste do Brasil. Revista Brasileira Oceanografia, v. 47, n. 1, p. 69-78, 1999.

COSTA, J.A; DA SILVA, D.F. Ciclos e períodos de eventos extremos na bacia hidrográfica do Rio Salgado (CE). Fortaleza, Congresso Técnico e Cientifico da Engenharia e Agronomia- CONTECC, 2015.

DA SILVA, D.F. Análise de Aspectos Climatológicos, Agronômicos, Ambientais e de Seus Efeitos Sobre a Bacia Hidrográfica do Rio Mundaú (AL e PE). Tese de Doutorado em Recursos Naturais, UFCG, Campina Grande, 2009.

DA SILVA, D.F.; LIMA, M.J.S.; SOUZA NETO, P.F.; GOMES, H.B.; SILVA, F.D.S.; ALMEIDA, H.R.R.C.; PEREIRA, M.P.S.; COSTA, R.L. Caracterização de eventos extremos e de suas causas climáticas com base no Índice Padronizado de Precipitação Para o Leste do Nordeste. Revista Brasileira de Geografia Física, v. 13, n. 2, p. 449-464, 2020.

DA SILVA, D.F.; KAYANO, M.T.; SOUSA, F.A.S. Uso de ferramentas estatísticas para acompanhamento climático e prevenção de riscos na Bacia Hidrográfica do rio Mundaú (Brasil). Revista Territorium, v. 17, p. 17-26, 2010.
DIAS, M.A.F.S. Eventos climáticos extremos. Revista USP, n. 103, p. 33-40, 2014.

GERSHUNOV, A.; BARNETT, T.P. Interdecadal modulation of ENSO teleconnections. Bulletin of the American Meteorological Society, v. 79, n. 12, p. 2715-2725, 1998.

GRIMM, A.M.; FERRAZ, S.E.T. Sudeste do Brasil: uma região de transição no impacto de eventos extremos da Oscilação Sul. Parte I: El Niño. Brasília, In: X Congresso Brasileiro de Meteorologia, 1998.

GROISSMAN, P.Y.; KNIGHT, R.W.; EASTERLING, D.R.; KARL, T.R.; HEGERL, G.C.; RAZUVAEV, V.N. Trends in intense precipitation in the climate record. Journal of Climate, n. 18, n. 9, p. 1326-50, 2005.

GUIMARÃES, R.M., ASMUS, C.I.R.F., BURDOF, A. Characterization of population exposure to organochlorines: a cluster analysis application. Revista Brasileira de Epidemiologia, v. 16, n. 2, p. 231-239, 2013.

HAYLOCK, M.R.; PETERSON, T.C.; ALVES, L.M.; AMBRIZZI, T.; ANUNCIAÇÃO, Y.M.T.; BAEZ, J.; BARROS, V.R.; BERLATO, M.A.; BIDEGAIN, M.; CORONEL, G.; CORRADI, V.; GARCIA, V.J.; GRIMM, A.M.; KAROLY, D.; MARENGO, J.A.O; MARINO, M.B.; MONCUNILL, D.F.; NECHET; D.; QUINTANA, J.; REBELLO, E.; RUSTICUCCI, M.; SANTOS, J.L.; TREBEJO, I.; VICENT, L. A. Trends in total and extreme South America rainfall in 1960-2000 and links with sea-surface temperatures. Journal of Climate, v. 19, n. 8, p. 14901512, 2006.

IPCC - Intergovernamental Panel on Climate Change. Working Group III - Mitigation of Climate Change. Disponível em http://www.iniciativaverde.org.br/biblioteca-nossaspublicacoes.php, acesso em 24/09/2016, 2014.

IPCC - Intergovernamental Panel on Climate Change. Special Report on the Ocean and Cryosphere in a Changing Climate. Pörtner, H.O.; Roberts, D.C.; Masson-Delmotte, V.; Zhai, P.; Tignor, M.; Poloczanska E.; Mintenbeck, K.; Alegría, A.; Nicolai, M.; Okem, A.; Petzold, J.; Rama, B.; Weyer, N.M. Disponível em https://www.ipcc.ch/site/ assets/uploads/sites/3/2019/12/

SROCC_FullReport_FINAL.pdf, acesso em 23/03/2020, 2019.

KAYANO, M.T.; OLIVEIRA, C.P. Diferenças associadas à oscilação decenal do Pacífico nas relações interanuais de precipitação na América do Sul e temperatura da superfície do mar. Zaragoza. In: Jornadas Científicas de la AME, 2008.

KENDALL, M.G. Rank Correlation Methods, 4th ed, Charles Griffin: London, 1975.

KOUSKY, V.E.; CHU, P.S. Fluctuations in annual rainfall for northeast Brazil. J. Meteor. Soc. Japan, v. 56, n. 5, p. 457466, 1978.

KERR, R.A. A now dawn for sun-climate links? Science,v. 271, n. 5254, p. 1360-1361, 1996.

MACEDO, M.J.H; GUEDES, R.V.S; SOUSA, F.A. S; DANTAS, F.R.C. Análise do índice padronizado de precipitação para o estado da Paraíba, Brasil. Revista Ambi-Água, v. 5, n. 1, p. 204-214, 2010.

MANN, H.B. Non-parametric tests against trend. Econometrica, v. 13, p. $245-259,1945$. 
MARENGO, J.A.O. Mudanças Climáticas Globais e seus Efeitos sobre a Biodiversidade: Caracterização do Clima Atual e Definição das Alterações Climáticas para o Território Brasileiro ao Longo do Século XXI. Brasília: MMA, p. 30-132, 2006.

MARENGO, J.A.O. Água e mudanças climáticas. Estudos Avançados, v. 22, n. 63, p. 83-96, 2008.

MARENGO, J.A.O. Mudanças climáticas, Condições Meteorológicas Extremas e Eventos Climáticos no Brasil. Disponível em http://www.fbds.org.br/cop15/ FBDS_MudancasClimaticas.pdf, acesso em 31-08-2017, 2016.

MCKEE, T.B.; DOESKEN, N.J.; KLEIST, J. The relationship of drought frequency and duration of time scales. In: Preprints Conference on Applied Climatology. Massachusetts: American Meteorological Society, p. 179-186, 1993.

MINUZZI, R.B.; SEDIYAMA, G.C; COSTA, J.M.N.; VIANELLO, R.L. Influência do fenômeno climático El Nino no período chuvoso da Região Sudeste do Brasil. Revista Geografia, v. 15, n. 2, p. 345-363, 2006.

MOLION, L.C.B. Aquecimento global, El Niños, manchas solares, vulcões e oscilação decadal do Pacífico. Revista Climanálise, v. 3, n. 1, p. 1-5, 2005.

ROCKWOOD, A.A.; MADDOX, R.A. Mesoscale and synoptic scale interactions leading to intense convection: The case of 7 June 1982. Weather and Forecasting, v. 3, p. 51-68, 1988.

ROLIM, G.S; CAMARGO, M.B.P; LANIA, D.G; MORAES, J.F.L. Classificação climática de Köppen e de Thornthwaite e sua aplicabilidade na determinação de zonas agroclimáticas para o Estado de São Paulo. Revista Bragantina, v. 66, n. 4, p. 711-720, 2007.

SANSIGOLO, C.A; KAYANO, M.T. Trends of seasonal maximum and minimum temperatures and precipitation in Southern Brazil for the 1913-2006 period. Theoretical and Applied Climatology, v. 101, n. 1-2, p. 209-216, 2010.

SANTOS, E.H.M.; GRIEBELER, N.P; OLIVEIRA, L.F.C. Variabilidade espacial e temporal da precipitação pluvial na bacia hidrográfica do Ribeirão João Leite-GO. Eng. Agríc., v. 31, n. 1, p. 78-89, 2011.

SANTOS, S.R.Q.; BRAGA, C.C.; SANSIGOLO, C.A.; SANTOS; A.P.P. Determinação de regiões homogêneas do índice de precipitação normalizada (SPI) na Amazônia Oriental. Revista Brasileira de Meteorologia, v. 32, n. 1, p. 111-122, 2017.
SERVAIN, J.; WAINER, I.; MCCREARY, J.P.; DESSIER, A. Relationship between the equatorial and meridional modes of climatic variability in the Tropical Atlantic. Geophysical Research Letters, v. 26, n. 4, p. 485-488, 1999.

SILVA, G.; DA SILVA, D.F. Análise da influência climática sobre a produção agrícola no semiárido cearense. Revista Brasileira de Geografia Física, v. 9, n. 2, p. 643-657, 2016.

SILVA, R.A.; SILVA, V.P.R.; CAVALCANTI, E.P; DOS SANTOS, D.N. Estudo da variabilidade da radiação solar no Nordeste do Brasil. Revista Brasileira Eng. Agrícola e Ambiental, v. 14, n. 5, p. 501-509, 2010.

SOUZA, E.B.; NOBRE, P. Uma revisão sobre o dipolo no Atlântico Tropical. Revista Brasileira de Meteorologia, v. 13, n. 1, p. 31-44, 1998.

OLIVEIRA M.J.; CARNEIRO C.D.R.; VECCHIA F.A.S.; BAPTISTA G.M.M. Ciclos climáticos e causas naturais das mudanças do clima. Terra e Didática, v. 13, n. 3, p. 149$184,2017$.

TEDESCHI, R.G. As Influências de Tipos Diferentes de ENOS na Precipitação e nos Seus Eventos Extremos Sobre a América do Sul. Tese de Doutorado em Meteorologia, Instituto Nacional de Pesquisas Espaciais, São José dos Campos, 224 p., 2013.

TEDESCHI, R.G.; GRIMM, A.M.; CAVALCANTI, I.F.A. Influence of central and east ENSO on precipitation and its extreme events in South America during austral autumn and winter. International Journal of Climatology, v. 36, p. $4797-4814$, 2016. DOI: $10.1002 /$ joc. 4670

WENG, H.; LAU, K.M. Wavelets, period doubling, and timefrequency localization with application to organization of convection over the Tropical Western Pacific. Journal of the Atmospheric Sciences, v. 51, n. 17, p. 2523-2541, 1994.

YEH, S.; KUG, J.B.; DEWITTE, B.; KNOW, M.H.; KIRTMAN, B.P. El Niño in a changing climate. Nature, v. 461, p. 511514, 2009.

ZUFFO, A.C. O sol, o motor das variabilidades climáticas. Revista DAE, v. 63, n. 198, p. 6-24, 2015.

License information: This is an open-access article distributed under the terms of the Creative Commons Attribution License (type CC-BY), which permits unrestricted use, distribution and reproduction in any medium, provided the original article is properly cited. 